\title{
Magnetic and photocatalytic properties of nanocrystalline $\mathrm{ZnMn}_{2} \mathrm{O}_{4}{ }^{\#}$
}

\author{
MENAKA, MOHAMMED QAMAR, SAMUEL E LOFLAND ${ }^{\dagger}$, \\ KANDALAM V RAMANUJACHARY ${ }^{\dagger \dagger}$ and ASHOK K GANGULI* \\ Department of Chemistry, Indian Institute of Technology, New Delhi 110 016, India \\ ${ }^{\dagger}$ Department of Physics and Astronomy, \\ ${ }^{\dagger \dagger}$ Department of Chemistry and Biochemistry, Rowan University, Glassboro, NJ-08028, USA
}

\begin{abstract}
The present study describes the synthesis of $\mathrm{ZnMn}_{2} \mathrm{O}_{4}$ nanoparticles with the spinel structure. These oxide nanoparticles are obtained from the decomposition of metal oxalate precursors synthesized by (a) the reverse micellar and (b) the coprecipitation methods. Our studies reveal that the shape, size and morphology of precursors and oxides vary significantly with the method of synthesis. The oxalate precursors prepared from the reverse micellar synthesis method were in the form of rods (micron size), whereas the coprecipitation method led to spherical nanoparticles of size, $40-50 \mathrm{~nm}$. Decomposition of oxalate precursors at low temperature $\left(4^{\circ} 0^{\circ} \mathrm{C}\right)$ yielded phase pure $\mathrm{ZnMn}_{2} \mathrm{O}_{4}$ nanoparticles. The size of the nanoparticles of $\mathrm{ZnMn}_{2} \mathrm{O}_{4}$ obtained from reverse micellar method is relatively much smaller $(20-30 \mathrm{~nm})$ as compared to those made by the co-precipitation $(40-50 \mathrm{~nm})$ method. Magnetic studies of nanocrystalline $\mathrm{ZnMn}_{2} \mathrm{O}_{4}$ confirm antiferromagnetic ordering in the broad range of $\sim 150 \mathrm{~K}$. The photocatalytic activity of $\mathrm{ZnMn}_{2} \mathrm{O}_{4}$ nanoparticles was evaluated using photo-oxidation of methyl orange dye under UV illumination and compared with nanocrystalline $\mathrm{TiO}_{2}$.
\end{abstract}

Keywords. Nanostructures; chemical synthesis; electron microscopy.

\section{Introduction}

Zinc manganese oxide, with spinel-like structure has attracted much attention because of its tremendous technological importance as catalysts (Bessekhaud et al 2005), solid electrolytes (Yang et al 1996), negative temperature coefficient (NTC) thermistor (Fritsch et al 2000) and as sensor materials (Sorita and Kawano 1996). $\mathrm{ZnMn}_{2} \mathrm{O}_{4}$ has a normal spinel structure with a tetragonal distortion $(c / a=1 \cdot 14)$ of the face centred pseudocubic cell having cell parameters of $a=8.087$ and $c=9.245 \AA$ (Asbrink et al 1999). The distortion (Jahn-Teller type) causes instability of the $\mathrm{Mn}^{+3}$ ion located at the octahedral site within the oxygen sublattice. Micron-sized particles of $\mathrm{ZnMn}_{2} \mathrm{O}_{4}$ have been prepared earlier by various methods like solgel (Monros et al 1995), solid-state reaction (Chhor et al 1986; Feltz and Jager 1988; Peiteado et al 2007; ElAiashy et al 1995) and coprecipitation methods (Rosenberg et al 1963). Zhang et al (2007) synthesized $\mathrm{ZnMn}_{2} \mathrm{O}_{4}$ nanoparticles of size $20-50 \mathrm{~nm}$ by a hydrothermal method, which requires $118 \mathrm{~h}$ (long time) for its completion. However, the above synthetic approaches do not have sufficient control on the size and morphology of the nanoparticles.

\footnotetext{
*Author for correspondence (ashok@ chemistry.iitd.ernet.in)

\#Dedicated to Prof. C N R Rao on his 75th birthday
}

The reverse micellar route is known to facilitate the control of size and morphology of various nanoparticles (Ahmad et al 2004, 2005; Ganguli et al 2007). The present study describes the synthesis of nanocrystalline $\mathrm{ZnMn}_{2} \mathrm{O}_{4}$ by two methodologies, (i) reverse micellar and (ii) coprecipitation method. In the reverse micellar method, a microemulsion system consisting of an oil phase, a surfactant and an aqueous phase are mixed appropriately to give a thermodynamically stable isotropic dispersion of aqueous phase in a continuous oil phase (Luisi and Straub 1984; Fang et al 1997). The size of the aqueous droplets (reverse micelles) is in the range of 5-20 $\mathrm{nm}$ and hence lead to an optically transparent microemulsion (Kuiry and Seal 2004). On mixing the two microemulsions, precipitation takes place due to the collision of the droplets containing the reactants. The reverse micellar route is of importance since it provides a convenient way to synthesize nanosized and nearly mono-dispersed nanoparticles. Various authors have reported the magnetic behaviour of $\mathrm{ZnMn}_{2} \mathrm{O}_{4}$ which shows the presence of antiferromagnetism in $\mathrm{ZnMn}_{2} \mathrm{O}_{4}$ with a broad variation in the Neel temperature (Aiyama 1966; Chhor et al 1986; Asbrink et al 1999). The origin of such variation is, however, not very clear. Asbrink et al (1999) reported a Neel temperature of $21.5 \mathrm{~K}$ (magnetic moment $=4.9 \mu_{\mathrm{B}} / \mathrm{Mn}$ ) while Aiyama (1966) claimed the Neel temperature to be around $250 \mathrm{~K}$. The unusually high Neel temperature of $\mathrm{ZnMn}_{2} \mathrm{O}_{4}$ could not be determined accurately using the susceptibility $(\chi-T)$ curve but was obtained using specific heat measurement (Aiyama 1966). 


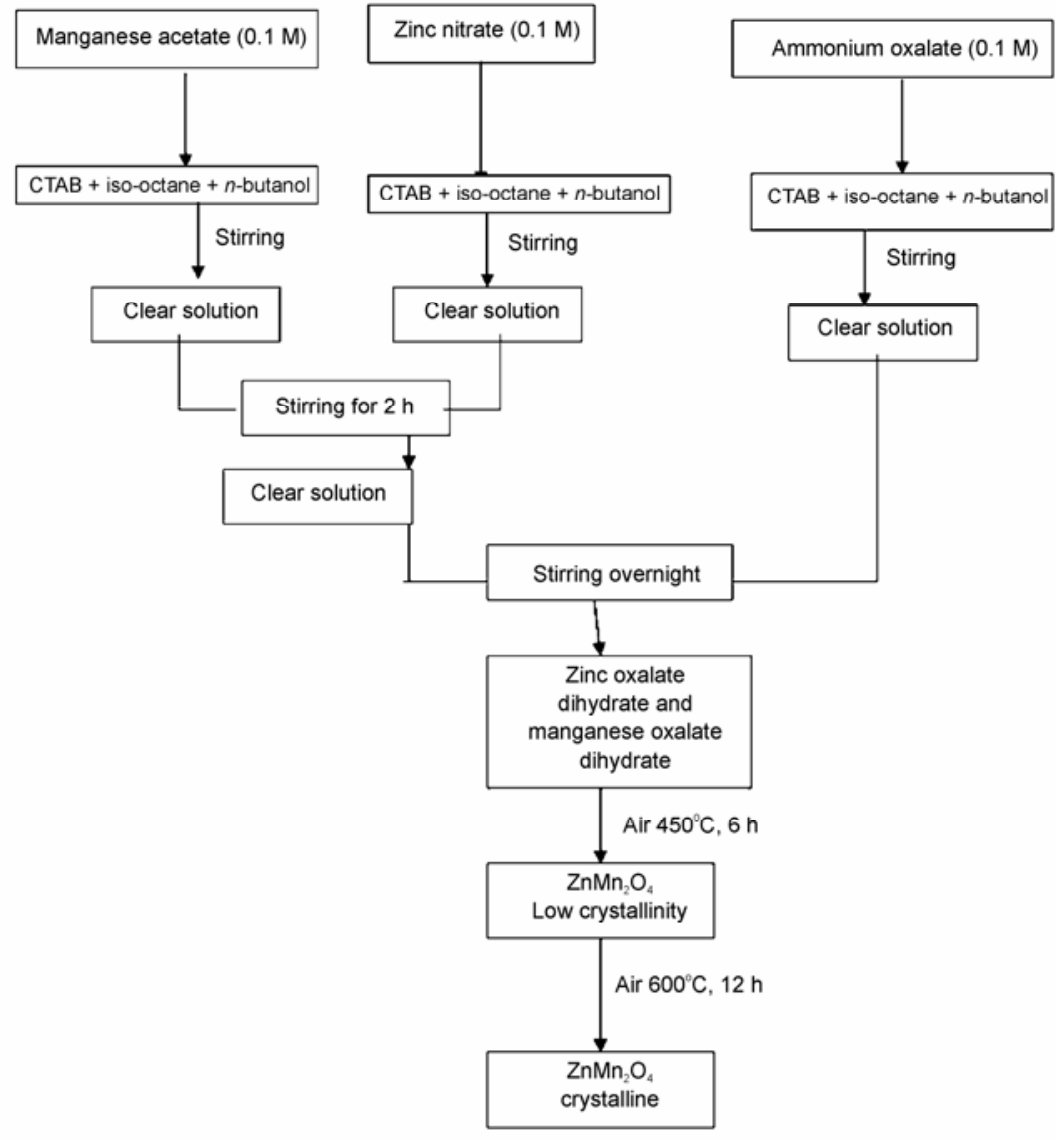

(a)

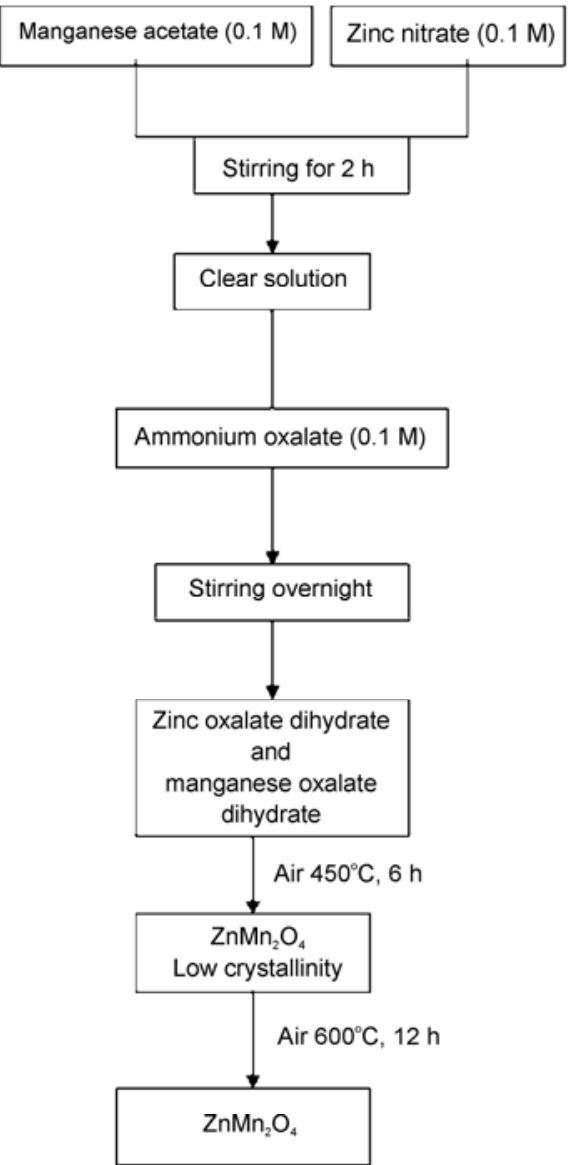

(b)

Figure 1. Flow chart indicating the method of synthesis of $\mathrm{ZnMn}_{2} \mathrm{O}_{4}$ using (a) reverse micellar method and (b) coprecipitation method.

Here we report the synthesis of rod-shaped zinc and manganese oxalate dihydrates (reverse micellar method) as well as spherical particles (coprecipitation method). Their decomposition yields pure $\mathrm{ZnMn}_{2} \mathrm{O}_{4}$ nanoparticles. The rods and nanoparticles have been characterized by powder X-ray diffraction (PXRD), thermogravimetric analysis (TGA), differential thermal analysis (DTA) and transmission electron microscopy (TEM). The magnetic behaviour of $\mathrm{ZnMn}_{2} \mathrm{O}_{4}$ nanoparticles was investigated using a Quantum Design Physical Properties Measurement system. The photocatalytic activity of $\mathrm{ZnMn}_{2} \mathrm{O}_{4}$ was evaluated spectrophotometrically (Bessekhaud et al 2005; Qamar et al 2008).

\section{Experimental}

We attempted to synthesize the mixed metal oxalate precursor, $\mathrm{ZnMn}_{2}\left(\mathrm{C}_{2} \mathrm{O}_{4}\right)_{3} \cdot x \mathrm{H}_{2} \mathrm{O}$, by the reverse micellar method following the procedure developed earlier for other oxalates (Ahmad et al 2004, 2005). Three micro- emulsions were prepared using cetyltrimethyl ammonium bromide (CTAB) as the surfactant, 1-butanol as the cosurfactant, isooctane as the non-polar phase and the aqueous solutions were made up of $0.1 \mathrm{M}$ of (i) zinc nitrate, (ii) manganese acetate and (iii) ammonium oxalate. The $\mathrm{Zn}^{+2}: \mathrm{Mn}^{+2}$ molar ratio of $1: 2$ was maintained in the starting reagents. The weight fraction of various constituents in the microemulsions was $16.86 \%$ of CTAB, $14 \cdot 1 \%$ of $n$-butanol, $58.91 \%$ of isooctane and $10 \cdot 11 \%$ of aqueous phase. The synthetic procedure (reverse micellar method) for the synthesis of oxalate precursor as well as oxide nanoparticles is summarized in a flow chart (figure la).

We have also synthesized the mixture of oxalates of zinc and manganese by the coprecipitation method using ammonium oxalate and mixture of manganese acetate and zinc nitrate. $10 \mathrm{ml}$ of $0 \cdot 1 \mathrm{~N}$ aq. zinc nitrate solution was slowly mixed with $20 \mathrm{ml}$ of $0 \cdot 1 \mathrm{~N}$ aq. manganese acetate. To this solution $30 \mathrm{ml}$ of $0 \cdot 1 \mathrm{~N}$ ammonium oxalate was slowly added and then stirred overnight. The oxide nanoparticles were obtained after decomposition of the 
precursors of zinc and manganese oxalate at a temperature of $450^{\circ} \mathrm{C}$ in air and to improve the crystallinity, further heated the sample at $600^{\circ} \mathrm{C}$ in air for $12 \mathrm{~h}$.

Powder X-ray diffraction studies were carried out on a Bruker D8 Advance diffractometer with Ni-filtered $\mathrm{Cu}$ $\mathrm{K} \alpha$ radiation using a step size of $0.02^{\circ}$ and a step time of $1 \mathrm{~s}$. Raw data were subjected to background correction and $\mathrm{K} \alpha 2$ lines were removed. The crystallite size was calculated from Scherrer's formula (Ahmad et al 2004). Thermogravimetric (TGA) and differential thermal analysis (DTA) experiments were carried out on a Perkin Elmer TGA and DTA system on well ground samples in a flowing nitrogen atmosphere with a heating rate of $5^{\circ} \mathrm{C} / \mathrm{min}$. Transmission electron microscopy (TEM) studies were carried out using a Tecnai $\mathrm{G}^{2} 20$ electron microscope operated at $200 \mathrm{kV}$. TEM specimens were prepared by dispersing the oxide powder in ethanol by ultrasonic

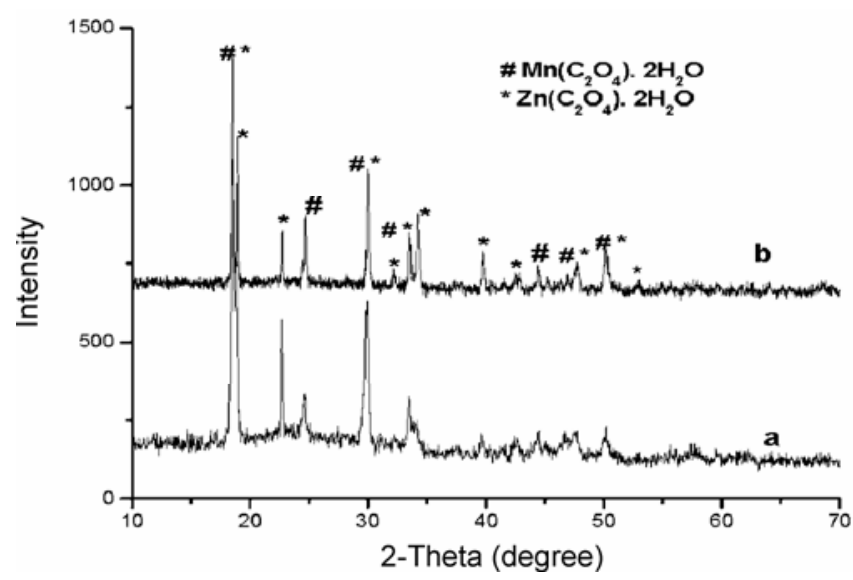

Figure 2. PXRD pattern of the metal oxalates obtained using a. reverse micellar and b. coprecipitation route

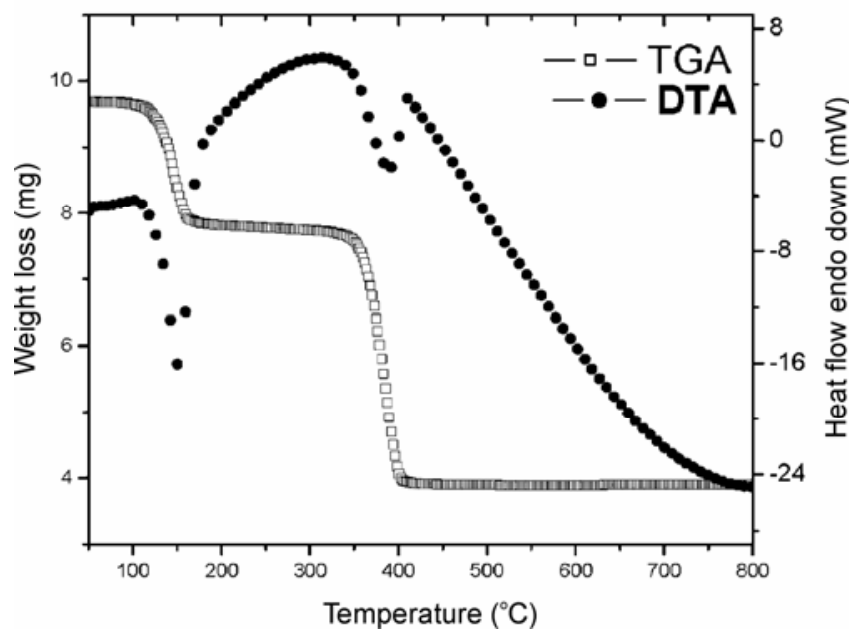

Figure 3. TGA/DTA plot for the decomposition of mixture of zinc oxalate and manganese oxalate prepared using reverse micellar route. treatment. A few drops were poured onto a porous carbon film supported on a copper grid and then dried in air. Temperature and field dependent magnetization measurements were carried out at temperatures ranging from $5-300 \mathrm{~K}$ in an applied field of $1 \mathrm{kOe}$ with a Quantum Design Physical Properties Measurement system.

The photocatalytic activity of $\mathrm{ZnMn}_{2} \mathrm{O}_{4}$ was evaluated with a photo-reactor made up of Pyrex glass equipped with a magnetic stirring bar. For irradiation experiments, $200 \mathrm{ml}$ of methyl orange dye of $0.5 \mathrm{mM}$ concentration was taken into the vessel and appropriate amount of the catalyst, ca $180 \mathrm{mg}$, of commercially available $\mathrm{TiO}_{2}$ nanopowder (Aldrich, 99.7\%) of $\sim 5 \mathrm{~nm}$ size and $20 \mathrm{mg}$ of
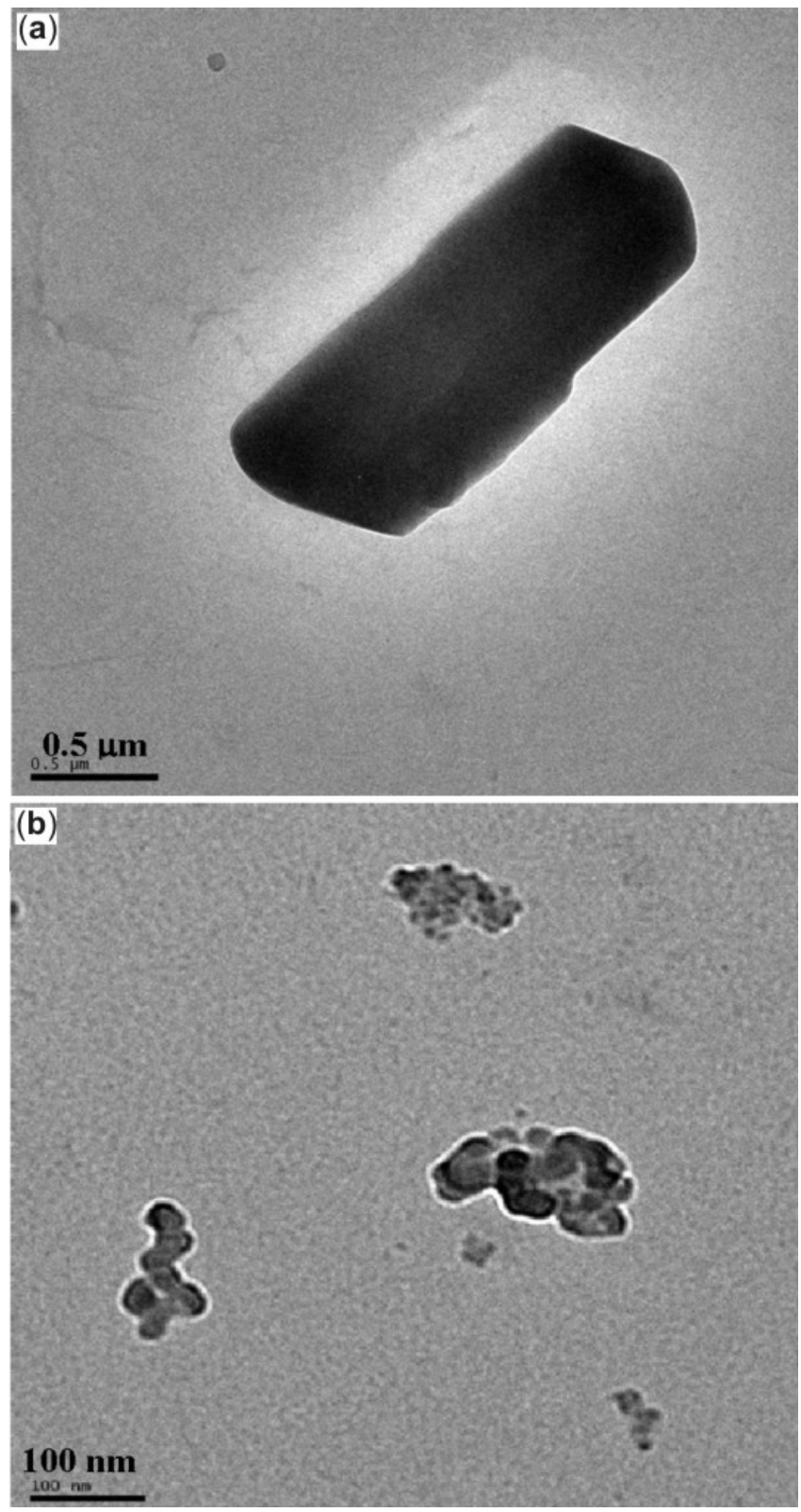

Figure 4. TEM image of the metal oxalates synthesized using (a) reverse micellar and (b) coprecipitation route. 
$\mathrm{ZnMn}_{2} \mathrm{O}_{4}$ of $\sim 25 \mathrm{~nm}$ size was added into the solution. Before irradiation, the solution was stirred for $15 \mathrm{~min}$ to allow the equilibration of the system so that the loss of methyl orange due to adsorption can be taken into account. The zero time reading was obtained from the blank solution kept in dark and then the solution was irradiated. Irradiation was carried out with a medium pressure mercury lamp and the samples were collected before irradiation and at regular interval during irradiation (Qamar et al 2008). The decrease in absorption intensity of the peak at $463 \mathrm{~nm}$ for the dye $(0.5 \mathrm{mM})$, on irradiation with time was monitored by measuring the change in absorbance using a UV-Vis spectrophotometer. The same experiment was carried out using pure $\mathrm{TiO}_{2}$ as well as pure $\mathrm{ZnMn}_{2} \mathrm{O}_{4}$ nanoparticles.

\section{Results and discussion}

The powder X-ray diffraction pattern of the precursor obtained by the reverse micellar method shows a mixture of manganese oxalate dihydrate and zinc oxalate dihydrate (figure 2a). The coprecipitation route also led to the formation of a mixture of the two oxalates (figure $2 b$ ). TGA of the oxalate precursor obtained from reverse micelle and coprecipitation method, shows two weight losses, the first weight loss is at around $140^{\circ} \mathrm{C}$ which corresponds to the loss of water molecule whereas the second weight loss is around $390^{\circ} \mathrm{C}$ and corresponds to the loss of $\mathrm{CO}$ and $\mathrm{CO}_{2}$, leading to the conversion of the oxalates to $\mathrm{ZnMn}_{2} \mathrm{O}_{4}$. The DTA studies also showed two endotherms corresponding to decomposition of the mixed oxalate precursors (figure 3).

Transmission electron microscopy of the oxalate precursor obtained by the reverse micellar method showed the formation of micron-sized rods (figure 4a). Several

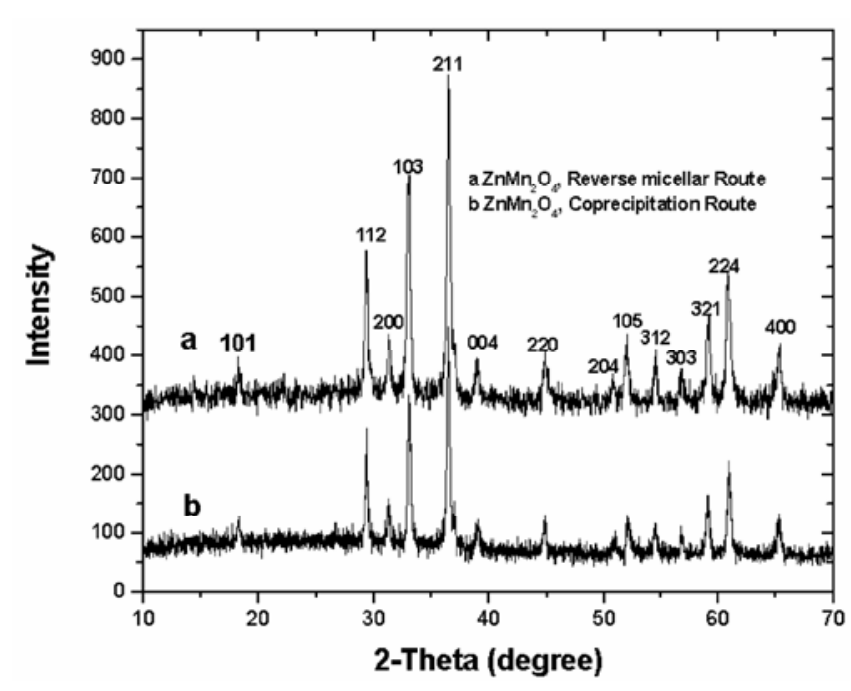

Figure 5. PXRD pattern of $\mathrm{ZnMn}_{2} \mathrm{O}_{4}$ synthesized at $600^{\circ} \mathrm{C}$ via a. reverse micellar and $\mathbf{b}$. coprecipitation method. transition metal carboxylates have shown the rod shaped morphology when synthesized using CTAB as a surfactant (Ahmad et al 2004, 2005; Ganguli et al 2007). The average dimension of the rods was $0.75 \mu \mathrm{m}$ (diameter) and $2 \mu \mathrm{m}$ (length) (figure $4 \mathrm{a}$ ). However, transmission electron microscopy of the oxalate precursor obtained using the coprecipitation route showed the formation of uniform nanoparticles in the range of $40-50 \mathrm{~nm}$ (figure 4b). The oxalates were calcined at $450^{\circ} \mathrm{C}$ for $6 \mathrm{~h}$ to obtain $\mathrm{ZnMn}_{2} \mathrm{O}_{4}$. The powder X-ray pattern of $\mathrm{ZnMn}_{2} \mathrm{O}_{4}$ (figure 5a) was indexed on the basis of a tetragonal cell with lattice parameters $a=b=5.709(1)$ and $c=9.238(4) \AA$ which is close to the reported lattice parameters of $\mathrm{ZnMn}_{2} \mathrm{O}_{4}$ (JCPDS 77-0470). From the refined lattice parameters it was observed that the $\mathrm{ZnMn}_{2} \mathrm{O}_{4}$ obtained via reverse micellar route was free from the mixed valence state of manganese cation (only $\mathrm{Mn}^{3+}$ ion is present). The $c / a$ ratio is 1.618 which is very close to the $c / a$ ratio calculated for the single crystal of $\mathrm{ZnMn}_{2} \mathrm{O}_{4}$ (Sorita and Kawano 1996). The crystallite size evaluated from X-ray line broadening was found to be $\sim 25 \mathrm{~nm}$ which is in close agreement with the particle size $(20-30 \mathrm{~nm})$ obtained from transmission electron microscopic (figure 6a) studies. HRTEM studies show the lattice fringes and confirm the single crystalline nature of the nanoparticles (figure 6b). Monophasic $\mathrm{ZnMn}_{2} \mathrm{O}_{4}$ was also synthesized by decomposing the mixture of zinc oxalate and manganese oxalate obtained by coprecipitation method. The average crystallite size was evaluated from X-ray line broadening and was found to be $\sim 40-50 \mathrm{~nm}$ which is in good agreement with the particle size $(40-50 \mathrm{~nm})$ obtained from the transmission electron microscopic studies (figure 7).

The magnetic properties of pure $\mathrm{ZnMn}_{2} \mathrm{O}_{4}$ (obtained by reverse micellar route) have been studied. The magnetization shows a broad transition at $\sim 150 \mathrm{~K}$ signalling the onset of anti-ferromagnetic ordering in this phase. This temperature falls well within the range of Neel temperatures reported in the literature (figure 8). No effective magnetic moment calculations were attempted in view of the broad and complicated magnetic transition, but the results are similar to Aiyama et al (1966) bulk $\mathrm{ZnMn}_{2} \mathrm{O}_{4}$.

The photocatalytic activity of $\mathrm{ZnMn}_{2} \mathrm{O}_{4}$ prepared by reverse micelles has been investigated by photo-oxidation of methyl orange dye as the probe molecule. The degradation of methyl orange dye in the presence of $\mathrm{ZnMn}_{2} \mathrm{O}_{4}$ (without $\mathrm{TiO}_{2}$ ) revealed that the absorbance of the contaminants remains more or less similar; however, a marked degradation of the dye was observed in the presence of $10 \% \mathrm{ZnMn}_{2} \mathrm{O}_{4}+\mathrm{TiO}_{2}$ (anatase $\sim 5 \mathrm{~nm}$ ), as illustrated in figures $9 \mathrm{a}-\mathrm{c}$. The rate of degradation of methyl orange observed in the reaction with the mixture $\left(\mathrm{ZnMn}_{2} \mathrm{O}_{4}\right.$ and $\mathrm{TiO}_{2}$ ) was low as compared to that of pure $\mathrm{TiO}_{2}$ (figure 9a). It is believed that the conduction band of $\mathrm{ZnMn}_{2} \mathrm{O}_{4}$ is higher (oxidation potential $=+0.062 \mathrm{eV}$ ) than that of $\mathrm{TiO}_{2}$ (oxidation potential $\sim-0.5 \mathrm{eV}$ ) (Bessekhaud et al 

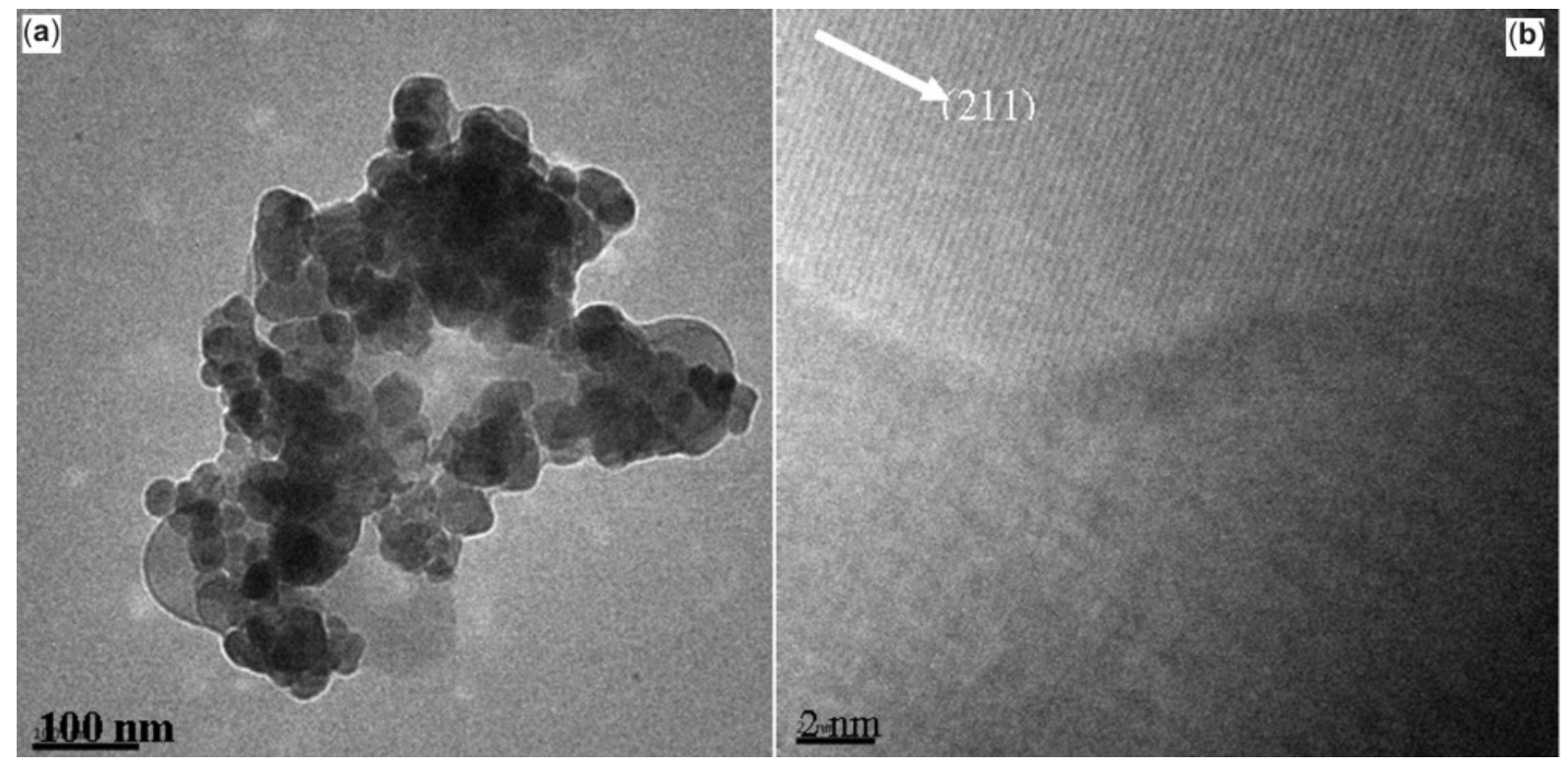

Figure 6. (a) TEM and (b) HRTEM image of $\mathrm{ZnMn}_{2} \mathrm{O}_{4}$ nanoparticles calcined at $600^{\circ} \mathrm{C}$ (using reverse micellar route).

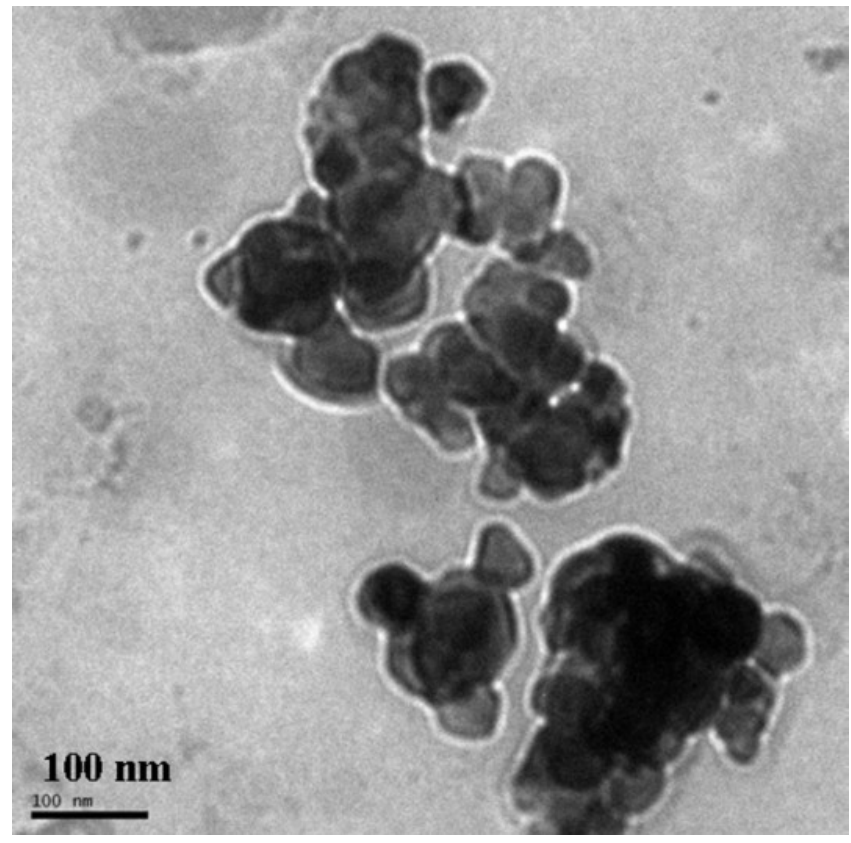

Figure 7. TEM images of $\mathrm{ZnMn}_{2} \mathrm{O}_{4}$ spherical nanoparticles synthesized at $600^{\circ} \mathrm{C}$ by coprecipitation method

2005) as shown in figure $10 \mathrm{a}$, so the electron generated in the conduction band of $\mathrm{ZnMn}_{2} \mathrm{O}_{4}$ cannot be transferred to the corresponding band of $\mathrm{TiO}_{2}$. Instead, the electron created on the conduction band of $\mathrm{TiO}_{2}$ can be transferred into the conduction band of $\mathrm{ZnMn}_{2} \mathrm{O}_{4}$ and thereby it decreases the efficiency when both semiconductors are irradiated (figures $10 \mathrm{a}-\mathrm{b}$ ). In other words, $\mathrm{ZnMn}_{2} \mathrm{O}_{4}$ facilitates the electron and hole pair recombination and decreases the efficiency of the $\mathrm{TiO}_{2}$. Figure $10 \mathrm{a}$ emphasizes the

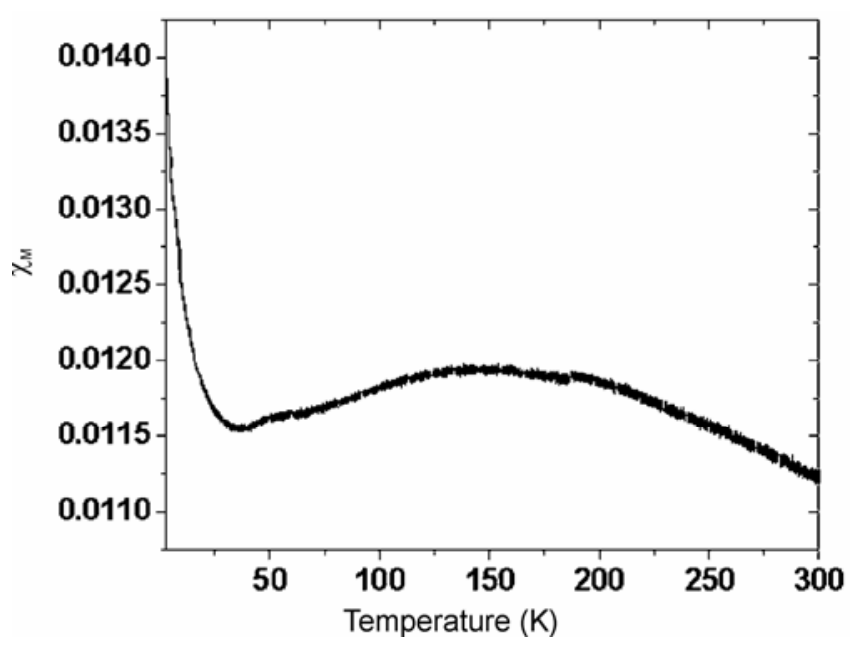

Figure 8. Plot of magnetic susceptibility of $\mathrm{ZnMn}_{2} \mathrm{O}_{4}$ with temperature.

general protocol for the degradation of the pollutant when $\mathrm{TiO}_{2}$ is coupled with a suitable semiconductor in the presence of UV-Vis light. Our data has some similarity with those on bulk $\mathrm{ZnMn}_{2} \mathrm{O}_{4}$ (Bessekhaud et al 2005).

\section{Conclusions}

Zinc manganese oxide $\left(\mathrm{ZnMn}_{2} \mathrm{O}_{4}\right)$ nanoparticles were successfully prepared from the oxalate precursors of zinc and manganese obtained by the reverse micellar as well as the coprecipitation methods. Both the methods yield monophasic and uniform compositionally agglomerated nanoparticles. The average particle size of $\mathrm{ZnMn}_{2} \mathrm{O}_{4}$ 


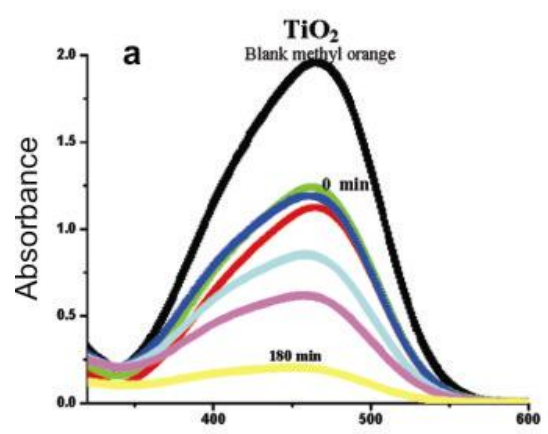

Wavelength $(\mathrm{nm})$
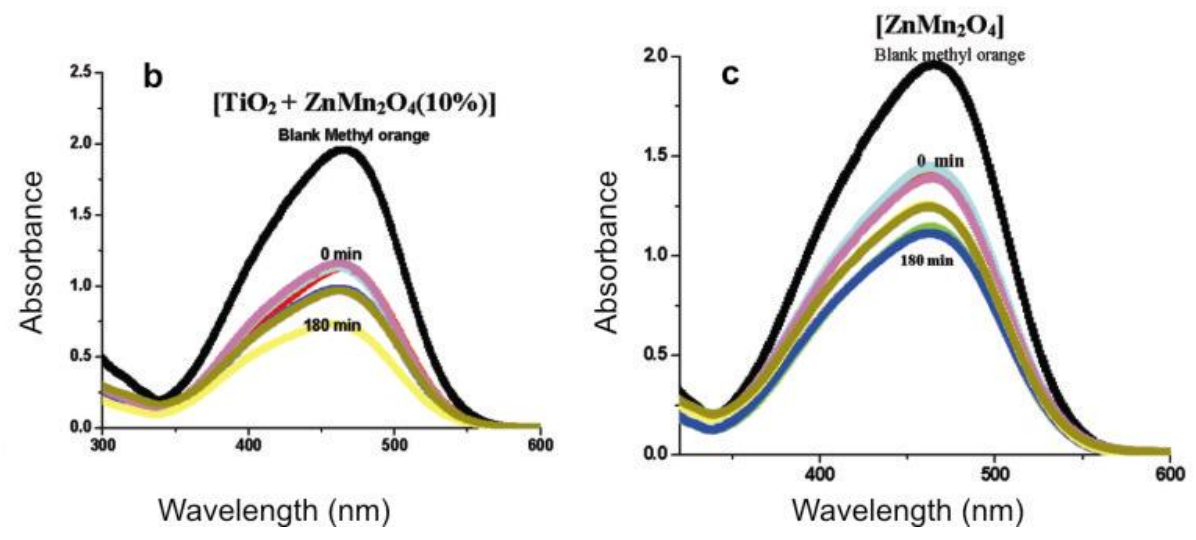

Figure 9. UV-Vis spectra showing the degradation of methyl orange under UV light using a. $\mathrm{TiO}_{2}$, b. mixture of $\mathrm{TiO}_{2}$ and $\mathrm{ZnMn}_{2} \mathrm{O}_{4}$ and c. $\mathrm{ZnMn}_{2} \mathrm{O}_{4}$.
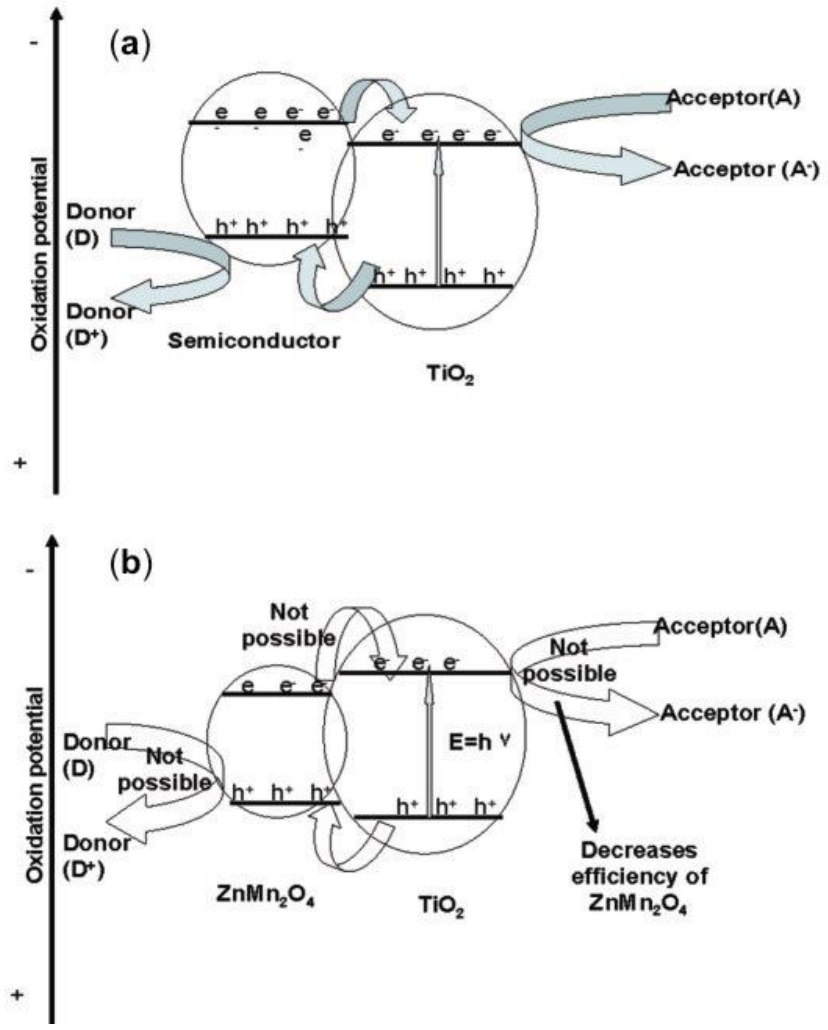

Figure 10. General energy diagram of a. coupled $\left(\mathrm{TiO}_{2}+\right.$ semiconductor) and b. $\mathrm{TiO}_{2}+\mathrm{ZnMn}_{2} \mathrm{O}_{4}$ for the photocatalytic oxidation reaction of the organic pollutant in the presence of UV light.

obtained from the reverse micellar method was in the range of $20-30 \mathrm{~nm}$ which is much smaller than that obtained by coprecipitation route $(40-50 \mathrm{~nm})$. Magnetization data shows a broad transition to antiferromagnetic order in the vicinity of $\sim 150 \mathrm{~K}$. Photocatalytic studies have also been performed which is in close agreement with that of bulk material.

\section{Acknowledgements}

Two of the authors (AKG) and (MQ) thank the Department of Science \& Technology, Govt. of India and CSIR, Govt. of India for financial support. (KVR) acknowledges the receipt of CP-STIO award from the Department of Science and Technology, Government of India. Menaka thanks UGC, Govt. of India for a fellowship. (SEL) acknowledges support by NSF MRSEC DMR 0520471.

\section{References}

Ahmad T, Ramanujachary K V, Lofland S E and Ganguli A K 2004 J. Mater. Chem. 143406

Ahmad T, Vaidya S, Sarkar N, Ghosh S and Ganguli A K 2005 Nanotechnology 171236

Aiyama Y 1966 J. Phys. Soc. Jpn 211684

Asbrink S, Waskowska A, Gerward L, Olsen J S and Talik E 1999 Phys. Rev. B60 12651

Bessekhaud Y, Robert D and Weber J V 2005 Catal. Today 101 315

Chhor K, Bocquet J F and Pommier C 1986 J. Chem. Thermodyn. 1889

El-Aiashy M K, Mazhar H S and Kamal S M 1995 Mater. Lett. 2497

Fang J, Wang J, Gan L M, Chew C H and Ng S C 1997 Nanostruct. Mater. 8499

Feltz A and Jager M 1988 Reactivity of Solids 6119

Fritsch S G, Chanel C, Sarrias J, Bayonne S, Rausset A, Alcobe $\mathrm{X}$ and Sarrio M L M 2000 Solid State Ionics 128233

Ganguli A K, Ahmed J, Vaidya S and Ahmad T $2007 \mathrm{~J}$. Nanosci. Nanotechnol. 71760

Kuiry S C and Seal S 2004 Encyclopedia of nanoscience and nanotechnology (ed.) H S Nalwa (CA, USA: American Scientific Publishers) p. 369

Luisi P L and Straub B E 1984 Reverse micelles (New York: Plenum)

Monros G, Carda J, Tena M A, Escribano P, Badenes J and Cordoncillo E 1995 J. Mater. Chem. 585 
Peiteado M, Caballero A C and Makovec D 2007 J. Solid State Chem. 1802459

Qamar M et al 2008 Catal. Today 1313

Rosenberg M, Nicolau P, Manaila R and Pausescu P 1963 J. Phys. Chem. Solids 241419
Sorita R and Kawano T 1996 Sensor and Actuators B35-36 274 Yang H, Yang Q H, Lu Y L and Li B X 1996 J. Power Sources 62223

Zhang X D, Wu Z S, Zang J, Li D and Zhang Z D 2007 J. Phys. Chem. Solids 681583 